\title{
Integrating Wikipedia editing into health professions education: a curricular inventory and review of the literature
}

\author{
Lauren A. Maggio (D) - John M. Willinsky (D) - Joseph A. Costello (D) - Nadine A. Skinner (D) Paolo C. Martin (D) \\ Jennifer E. Dawson (iD)
}

Received: 25 March 2020 / Revised: 12 September 2020 / Accepted: 15 September 2020 / Published online: 8 October 2020 (C) The Author(s) 2020

\begin{abstract}
Introduction Wikipedia is an online encyclopedia read by millions seeking medical information. To provide health professions students with skills to critically assess, edit, and improve Wikipedia's medical content, a skillset aligned with evidence-based medicine (EBM), Wikipedia courses have been integrated into health professions schools' curriculum. This literature review and curricular inventory of Wikipedia educational initiatives provides an overview of current approaches and identifies directions for future initiatives and research.

Methods Five databases were searched for articles describing educational interventions to train health professional students to edit Wikipedia. Course dash-
\end{abstract}

\section{Disclaimer The views expressed in this article are those of the authors and do not necessarily reflect the official policy or position of the Uniformed Services University of the Health Sciences, the U.S. Department of Defense, or the U.S. Government.}

Electronic supplementary material The online version of this article (https://doi.org/10.1007/s40037-020-00620-1) contains supplementary material.

\section{A. Maggio $(\square)$ \\ Department of Medicine, Uniformed Services University of the Health Sciences, Bethesda, MD, USA lauren.maggio@usuhs.edu}

J. M. Willinsky · N. A. Skinner · P. C. Martin Graduate School of Education, Stanford University, Stanford University, Stanford, CA, USA

\section{J. A. Costello}

Uniformed Services University of the Health Sciences in Bethesda, Bethesda, MD, USA

\section{J. E. Dawson}

CHEO Research Institute, and the Wikipedian in Residence for Cochrane, Ottawa, Ontario, Canada boards, maintained by Wiki Education (Wiki Edu), were searched for curricular materials. From these sources, key details were extracted and synthesized, including student and instructor type, course content, educational methods, and student outcomes.

Results Six articles and 27 dashboards reported courses offered between 2015 and 2019. Courses were predominantly offered to medical and nursing students. Instructors delivered content via videos, live lectures, and online interactive modules. Course content included logistics of Wikipedia editing, EBM skills, and health literacy. All courses included assignments requiring students to edit Wikipedia independently or in groups. Limited details on assessment of student learning were available.

Discussion A small but growing number of schools are training health professions education students to improve Wikipedia's medical content. Course details are available on Wiki Edu dashboards and, to a lesser extent, in peer-reviewed publications. While more needs to be done in conducting and sharing assessment of student learning, integrating Wikipedia into health professions education has potential to facilitate learning of EBM and communication skills, improve Wikipedia's online content, and engage students with an autonomous environment while learning. Future considerations should include a thorough assessment of student learning and practices, a final review of student edits to ensure they follow Wikipedia's guidelines and are written in clear language, and improved sharing of teaching resources by instructors.

Keywords Wikipedia - Evidence-based medicine · Critical appraisal 


\section{Introduction}

Wikipedia is an online encyclopedia consisting of over 6 million English-language entries, which is viewed more than 4.5 million times per hour, making it the seventh most visited site on the internet $[1,2]$. While Wikipedia covers a wide range of topics, 30,000 English-language entries are dedicated to medical topics [2], which receive 10 million page-views per day across 286 languages [3]. Readers include patients and their families in search of information to prepare for health provider appointments or to understand information provided in such visits $[4,5]$. Many health professionals and students also consult Wikipedia, whether to provide patient care or study [6-9].

The nature of Wikipedia, which allows anyone to edit its entries, has raised concerns about health professionals and students using Wikipedia, non-medical professionals relying on it for medical information, and the potential impact on public health $[3,10]$. To address these concerns, health professions schools have launched courses to train learners how to critically appraise and edit Wikipedia. For example, at the University of California, San Francisco, faculty offer medical and pharmacy students courses on improving Wikipedia's quality [11, 12]. At Queen's University, all first-year medical students are required to take the course, Critical Appraisal, Research and Lifelong Learning, a major component of which trains students to critically assess and contribute to Wikipedia's medical content [13]. The efforts of the Queen's University students in 2017 amounted to more than 1700 edits on 17 health topics, which were viewed over 3 million times in under a year.

At Queen's University and other institutions, faculty have leveraged Wikipedia editing initiatives to support teaching evidence-based medicine (EBM) [13, 14]. EBM is the "conscientious, explicit, and judicious use of current best evidence in making decisions about the care of individual patients" [15]. Most health professions schools are required to train students in EBM, which includes teaching learners to ask clinical questions, acquire and critically appraise information, and apply the information to a patient's care based on clinical expertise and patient preferences [16, 17]. Wiki Education (Wiki Edu), a nonprofit started by the Wikimedia Foundation, provides support for Wikipedia educational initiatives across North America. To support initiatives across a variety of disciplines, Wiki Edu provides online dashboards that facilitate course management, track editing progress and impact, and provide access to interactive training materials.

A recent scoping review focused broadly on situating Wikipedia as a health information resource [18]. While valuable, this review provides limited information on educational methods utilized, content covered, and course evaluation techniques used in educational initiatives. Moreover, this review only includes educational initiatives described in the peer reviewed literature, which has been suggested as a narrow approach [19]. Therefore, health professions instructors interested in integrating Wikipedia into their teaching have limited synthesized evidence to guide their training, which could lead to wasted instructor effort and suboptimal learning experiences. Thus, this study reviews online curricular materials and the relevant literature with an eye to provide educators with a detailed and holistic view of current approaches to using Wikipedia in health professions education (HPE) and to identify directions for future educational initiatives and research.

\section{Methods}

\section{Data collection: Curricular inventory}

On December 4, 2019, JC scanned Wiki Edu's dashboards to identify courses offered to HPE students [20]. A dashboard is a website provided to instructors by Wiki Edu. Dashboards are designed to serve as an information and communication hub for faculty, students, and Wiki Edu support staff engaged in courses. Dashboards, which instructors can tailor, provide tools to coordinate class assignments, track student edits, and serve as a platform to host course instructor and Wiki Edu educational materials (see Fig. 1 in the Electronic Supplementary Material).

JC reviewed all the dashboard titles indexed as: Communicating Science and Students in the Health Professions to determine course audience. If the audience was unclear, he reviewed the dashboard's content. If still unclear, the instructor, institution, and course name were googled to identify the course's audience.

A dashboard was included if it reported that participating HPE students made at least one edit to a Wikipedia article. Dashboards also had to feature key course details, such as those found on the course timeline, to enable the extraction of relevant course data. We excluded dashboards that only used the dashboard's tracking features (e.g., counts of student edits), but did not include curricular materials.

In the dashboard review, JC identified those courses that had been offered multiple times (e.g., a course offered in 2018 and 2019). In these cases, we included only the most recent dashboard, rationalizing that the latest iteration potentially reflected iterative lessons learned.

\section{Data collection: Literature review}

To identify relevant articles, LM and JC, both with backgrounds in information science, met three times to design search strategies optimized for multiple databases. On December 18, 2019, JC used the collaboratively designed searches to systematically search MEDLINE via Ovid, Embase, CINAHL, ERIC, and Web 
of Science. Searches combined controlled vocabulary terms and keywords (see Appendix A, in the Electronic Supplementary Material, for searches). Searches were limited to English. No date restrictions were applied. We also handsearched the references of included articles. Citations were managed in EndNote.

For full-text review, we included those articles describing curricular initiatives offered in health professions education (HPE) that were defined as programs leading towards careers in patient care. Articles were excluded if they described interventions using wiki software, but not specifically Wikipedia. We also excluded those using Wikipedia, but not as part of a curriculum or course.

JC and NS independently reviewed article titles and abstracts. For articles that were unclear, LM served as a tiebreaker.

\section{Data extraction}

We designed our data extraction tool by drawing on our backgrounds and experiences, which include training in information science and teaching Wikipedia to medical students (JC, LM) and experience in education and community health and prevention research (PM). The tool captured details including, but not limited to, student and instructor type, course content, educational methods, and student outcomes. See https://doi.org/10.6084/m9. figshare.12672179 for the data extraction tool. JC and LM independently extracted data from journal articles. JC and PM independently extracted dashboard data. LM, JC, and PM met via conference call to discuss and resolve coding differences.

\section{Synthesis and analysis}

We used Google Sheets to generate summary reports and descriptive statistics. We then collectively discussed similarities and differences in the initiatives and brainstormed implications for future educational initiatives and research.

\section{Results}

We included 27 dashboards [21-47] and six articles ([11-14, 48, 49]; see Fig. 2 in the Electronic Supplementary Material). Four articles $[11,12,48,49]$ described earlier accounts of six educational interventions also captured in our dashboard inventory, resulting in a considerable overlap between it and the literature review. For example, we include dashboard details from Azzam's 2019 course and Azzam's article that describes earlier iterations of the same course $[11,23]$. We first report dashboard results then article results.

\section{Dashboard results}

Courses were offered between 2015 and 2019, reflecting a growth in interest (Tab. 1). Courses ran from two [33] to 22 weeks [29], with an average of eight weeks. Courses were offered to medical $(n=6)[23,29,31,32$, $34,44]$, nursing $(n=4)$ [27, 35, 41, 47], and audiology $(n=2)$ students $[40,45]$, among the leading areas that could be identified. Due to limited dashboard details, we were unable to determine the discipline in 12 courses, or if students were in the pre-clinical or clinical phase of their studies. Course enrollment ranged from one [38] to 133 students [29].

\section{Instructors}

Instructors included physicians, librarians, nurses, and pharmacists. In two instances, students served as instructors [28, 44]. While we limited our analysis to the most recent dashboard iterations, 16 instructors had previously offered courses. For example, Lebowitz offered a course in 2017, 2018, and 2019 [36]. All courses were supported by Wiki Edu staff members, which was associated with the use of the dashboard.

\section{Dashboard focus}

Wiki Edu dashboards are intended to support courses for training students to edit Wikipedia's health pages. However, several courses integrated Wikipedia assignments as an approach for students to apply their learning of medical topics. For example, the course, Foundations of Clinical Trauma Psychology, which focused on trauma disorders and treatments, incorporated a Wikipedia assignment to allow students to apply and broadly share their newly acquired knowledge [26]. In a course on medical-related linguistic translation, Wikipedia was specifically used to provide students opportunities to apply their medical translation skills and contribute to Wikipedia's Spanishlanguage version [38]. In this regard, several instructors highlighted Wikipedia as a conduit for students' work to have impact beyond the classroom. To facilitate this goal, three instructors addressed health literacy in their courses to ensure students' Wikipedia edits would be appropriate for its public audience

Table 1 WikiEdu dashboard courses $(n=27)$ by year in health professions education (HPE)

\begin{tabular}{|c|c|c|c|c|c|}
\hline Year & Courses & Students & Articles edited & Edits made & HPE areas \\
\hline 2019 & 18 & 460 & 309 & 12,081 & Medicine, nursing, audiology, biomedical, translation \\
\hline 2018 & 3 & 32 & 36 & 652 & Medicine, nursing, audiology \\
\hline 2017 & 5 & 126 & 101 & 1,690 & Medicine, nursing, pharmacology, audiology, research \\
\hline 2016 & 1 & 119 & 31 & 1,190 & Pharmacology \\
\hline
\end{tabular}


[23, 24, 28]. For example, one course contained the lecture, "Writing for the Public, Considerations About Health Literacy," and provided learners a readability calculator and guide for avoiding medical jargon [24].

\section{Educational methods}

Instructors delivered content through videos, live lectures, guest speakers, and Wiki Edu modules. For example, four instructors incorporated guest lecturers with three being librarian-led [24, 28, 29, 36]. All course dashboards included Wiki Edu modules, which were primarily presented as text documents, but also included videos and quizzes. We identified 44 distinct Wiki Edu modules across the dashboards, including those focused on the mechanics of editing Wikipedia, such as "Contributing Images and Media Files" (included in 25 courses) and "Editing" and "Drafting in the Sandbox" (14), while other modules covered broader topics, such as "Peer Review" (21). (See Appendix B, in the Electronic Supplementary Material, for the modules included.) All courses include the "Wikipedia Policies" module, which introduced the overall ethos of Wikipedia and its "five pillars," which encourages editing from a neutral point of view and treating all editors with respect and civility [50].

Seventeen instructors customized their dashboards to orient students to the course. For example, five instructors supplemented Wiki Edu modules in their orientation materials with video and audio files, which often featured the instructors themselves [23, 24, 28, $31,36]$. Four instructors required full-day, on-site orientation sessions [23, 24, 28, 36].

Two dashboards specifically mentioned EBM [27, 34]. However, through Wiki Edu modules and additional instructor efforts, such as guest speakers and library resource guides, learners were trained in EBM skills, including to identify and articulate knowledge gaps (23 courses) and acquire (8) [23-25, 28, 31, 32, 34,36 , appraise (26), and apply (26) information.

Four instructors in five courses linked or embedded additional resources in the dashboards, such as cloud apps (e.g., GoogleDocs) for document sharing [21-23, 28, 31], while five instructors utilized video conferencing tools (e.g., Zoom) to host synchronous online sessions and digital office hours [23, 24, 28, $31,36]$. One instructor linked to their institution's learning management system [47]. All courses utilized the Wikipedia-specific "My Sandbox" feature, which is a tool offered by Wikipedia that allows students to practice drafting edits in a simulated Wikipedia environment, prior to making live changes to Wikipedia. In addition to providing a low-stakes environment for practice editing, instructors encouraged or in some cases required students to request peer review of their edits while they were in My Sandbox.

\section{Wikipedia assignments}

All courses assigned students to edit a Wikipedia article required the application of EBM skills to iden- tify gaps in a page's content, acquire and appraise information to fill the gap, and then apply that information to make Wikipedia edits. Students primarily completed assignments independently. However, in nine courses students could work independently or in groups [21, 22, 27, 32, 36, 41, 42, 45, 47] and in four, instructors had students work in groups [25, 30, 33, 34]. In two courses we were unable to make such a determination [26, 44]. In 12 courses, students self-selected their article to edit. To guide their choice, seven instructors assigned the Wiki Edu modules "Finding Your Article" [21, 23, 28, 31, 38, 39, 44] and four assigned "Choose Your Article" [21, 38, 39, 47]. Fourteen instructors required students to select articles based on the course topic and/or select from an instructorprovided list. A single instructor assigned students an article [25].

Students were also frequently assigned to peer review fellow students' work (24 courses) and to respond to peer comments (21), which was supported by a Wiki Edu module (21) and/or Wiki Edu's Peer Review Rubric [23, 28, 31, 37, 51]. Fourteen courses also required that students make final presentations describing their edits. Less common assignments included: reflective essays [27, 30, 32, 39, 43], work-inprogress reports [23, 24, 28, 31, 36, 42], and requesting students nominate work for the "Did you know?" feature on Wikipedia [22, 42, 45, 46].

\section{Student assessment and course evaluation}

Beyond assignments, dashboards provided limited details on assessments of student learning (apart from self-assessments in course evaluations). However, there was evidence of overall course evaluations and evaluations of each course's impact on Wikipedia. For example, five courses included end-of-course feedback sessions [23, 24, 28, 31, 36] and in one course students completed a final survey [32]. The 27 dashboards reflecting the work of 737 HPE students, indicated that 15,613 edits had been made on 477 articles, including the addition of 4,682 references and 42 images, which had been viewed 42.2 million times as of January 23, 2020.

\section{Literature results}

The six articles included covered eight courses-for which we provide a summary of general characteristics (Tab. 2) and course objectives (see Table in the Electronic Supplementary Material)—with only two courses not featured in the dashboard inventory [13, 14]. Courses were offered solely to medical students and pharmacy students, while one was interdisciplinary. Three authors reported multiple offerings of the course, making it difficult to discern the number of enrolled students per offering [11, 13, 14]. For example, Badgett reported two course offerings with one cohort of students enrolled in 2007 and the other in 2008 for a total of 39 learners taught [14]. Course 
Table 2 Characteristics of educational initiatives $(n=8)$ to teach Wikipedia editing to HPE students as reported in the literature

\begin{tabular}{|c|c|c|c|c|c|c|c|}
\hline Author, year & $\begin{array}{l}\text { Students (co- } \\
\text { horts) }\end{array}$ & Audience & Level & Instructor type & Duration & Status & Setting \\
\hline Apollonio, 2018 [12] & 119 & Pharmacy & Preclinical & $\begin{array}{l}\text { Unspecified; near peer stu- } \\
\text { dents }\end{array}$ & 9 weeks & Required & USA \\
\hline Azzam, 2017 [11] & $43(4)$ & Medical & Clinical & Instructors, librarians & 4 weeks & Elective & USA \\
\hline Badgett, 2011 [14] & $39(2)$ & Medical & Clinical & Unspecified & Unspecified & Elective & USA \\
\hline $\begin{array}{l}\text { Evenstein, } 2017 \\
\text { [49] }\end{array}$ & 62 & $\begin{array}{l}\text { Medical, dental, PhD, faculty, } \\
\text { staff }\end{array}$ & Unspecified & Faculty & Semester & Elective & Israel \\
\hline $\begin{array}{l}\text { Joshi, } 2019 \text { [48] } \\
\text { (MUSC) }\end{array}$ & $50(2)$ & Medical & Clinical & Faculty, librarians & 4 weeks & Elective & USA \\
\hline Joshi, 2019 (UCF) & 12 & Medical & Clinical & Faculty, librarians & 4 weeks & Elective & USA \\
\hline Joshi, 2019 (UCSF) & $16(3)$ & Medical & Clinical & Faculty, librarians & 4 weeks & Elective & USA \\
\hline Murray, 2020 [13] & 101 & Medical & Preclinical & $\begin{array}{l}\text { Unspecified, Wikipedia medi- } \\
\text { cal editor }\end{array}$ & Unspecified & Required & Canada \\
\hline
\end{tabular}

instructor identities were vague with authors noting those teaching simply as faculty or instructors without indication of profession except in the case of librarians, which were reported in four courses [11, 48]. In Apollonio's course near-peer students who had previously completed the course taught a handson demonstration session [12]. Five authors stated course objectives, which related to EBM and enhancing Wikipedia's content (see Table in Electronic Supplementary Material).

\section{Educational methods}

All instructors blended in-person and online elements (e.g., hands-on skills labs, recorded lectures). For example, the three courses reported by Joshi used teleconference software to enable students to remotely attend weekly meetings [48]. Except for Badgett's course, which was offered before Wiki Edu's founding, all courses utilized Wiki Edu modules and dashboards. Evenstein's course also described using the institution's learning management system, Moodle, to organize course material. Of note, all courses focused on the English-language version of Wikipedia, except for Evenstein's, which edited the Hebrew-language Wikipedia [49].

\section{Assignments}

Instructors required students to complete a Wikipedia editing assignment (Tab. 3). Students were provided varying levels of autonomy in selecting a Wikipedia article to edit. For those that were prescriptive, article selection was commonly related to the course's topic. As a component of the editing assignment, three courses required students to peer review each other's edits [13, 48, 49]. We propose that by completing these assignments students had the opportunity to practice EBM skills.

\section{Student assessment and course evaluation}

Instructors analyzed student Wikipedia edits to assess student learning, while utilizing course surveys, focus groups, and interviews to evaluate their students and courses (which included student self-assessments of learning) (Tab. 3). Primarily surveys queried students' satisfaction, but also self-perceived knowledge of Wikipedia and intentions to continue editing. Apollonio surveyed students at three points in the course using knowledge questions to objectively gauge increases in students' knowledge of Wikipedia's editing processes [12].

Students reported overall satisfaction with the courses and self-perceived improvements in their knowledge and skills. For example, the majority of students in the three courses described by Joshi selfreported increases in their ability to practice EBM [48]. Apollonio, based on pre-post surveys, concluded that her students' knowledge of Wikipedia editing improved by course end [12]. Authors also analyzed students' survey free-text responses. For example, by analyzing write-in comments, Murray identified course elements that the students appreciated and those identified as barriers, such as difficulties engaging with the broader Wikipedia editor community and students' hesitancy to make live edits [13]. Additionally, Evenstein's students described appreciating the opportunity to give back to the community via their edits, but also expressed that certain course elements (e.g., insufficient time dedicated to learning particular tasks) hindered the experience [49]. Interview and focus group data presented a similar mixed picture. Azzam's students described difficulties in ensuring the readability of their edits and lamented that editing was more work than expected, but also highlighted that "it feels good to contribute to Wikipedia" and that they appreciated the potential global significance of their edits [11].

Four instructors analyzed the number of student edits made and references added or deleted as a mea- 
Table 3 Details of educational activities, assignments and evaluation from courses to teach Wikipedia editing to HPE students

\begin{tabular}{|c|c|c|}
\hline Author & Educational activities & Assignments \\
\hline $\begin{array}{l}\text { Apollonio } \\
2018[12]\end{array}$ & $\begin{array}{l}\text { - Complete readings and } \\
\text { Wiki Edu modules } \\
\text { - Attend in-person } \\
\text { project overview and } \\
\text { editing session }\end{array}$ & $\begin{array}{l}\text { In small groups, edit instructor-se- } \\
\text { lected Wikipedia pages }\end{array}$ \\
\hline $\begin{array}{l}\text { Azzam, } \\
2017[11]\end{array}$ & $\begin{array}{l}\text { - Participate in in-person } \\
\text { 2-day orientation } \\
\text { - Attend optional virtual } \\
\text { instructor office hours }\end{array}$ & $\begin{array}{l}\text { Independently edit Wikipedia page } \\
\text { of student's choice }\end{array}$ \\
\hline $\begin{array}{l}\text { Badgett, } \\
2011 \text { [14] }\end{array}$ & $\begin{array}{l}\text { - Attend 4-hour in-per- } \\
\text { son session } \\
\text { - Complete online train- } \\
\text { ing (unspecified) }\end{array}$ & $\begin{array}{l}\text { Independently edit a Wikipedia page } \\
\text { of student's choice }\end{array}$ \\
\hline $\begin{array}{l}\text { Evenstein, } \\
2017 \text { [49] }\end{array}$ & $\begin{array}{l}\text { - Attend in-person ses- } \\
\text { sions } \\
\text { - Participate in online } \\
\text { discussion forums on } \\
\text { Moodle }\end{array}$ & $\begin{array}{l}\text { - Independently write a Wikipedia } \\
\text { page from an instructor-curated } \\
\text { list } \\
\text { - Peer review classmate } \\
\text { - Final presentation }\end{array}$ \\
\hline $\begin{array}{l}\text { Joshi, } \\
2019[48] \\
\text { (MUSC, } \\
\text { UCF, } \\
\text { UCSF) }\end{array}$ & $\begin{array}{l}\text { - Attend in-person orien- } \\
\text { tation session } \\
\text { - Complete Wiki Edu } \\
\text { modules } \\
\text { - Attend weekly } \\
\text { work-in-progress } \\
\text { support sessions }\end{array}$ & $\begin{array}{l}\text { - Independently or in teams edit } \\
\text { a Wikipedia article of choice or } \\
\text { from an instructor-curated list } \\
\text { - Peer review a classmate's work } \\
\text { - Final presentation }\end{array}$ \\
\hline $\begin{array}{l}\text { Murray, } \\
2020 \text { [13] }\end{array}$ & $\begin{array}{l}\text { Complete Wiki Edu mod- } \\
\text { ules }\end{array}$ & $\begin{array}{l}\text { - Independently and in small } \\
\text { groups critique Wikipedia pages } \\
\text { flagged for improvement } \\
\text { - Locate information to improve } \\
\text { page } \\
\text { - Peer review another group's } \\
\text { proposed edits }\end{array}$ \\
\hline
\end{tabular}

\begin{tabular}{|c|c|}
\hline Learning assessment & Course evaluation \\
\hline $\begin{array}{l}\text { Analysis of Wikipedia } \\
\text { edits (edits found to } \\
\text { improve Wikipedia } \\
\text { content quality) }\end{array}$ & $\begin{array}{l}\text { Surveys at multiple timepoints in the course } \\
\text { (students reported knowledge of Wikipedia editing } \\
\text { processes increased) }\end{array}$ \\
\hline $\begin{array}{l}\text { Analysis of Wikipedia } \\
\text { edits (edits found to } \\
\text { improve quality of } \\
\text { Wikipedia content, } \\
\text { including readability) }\end{array}$ & $\begin{array}{l}\text { Interviews and focus groups (students credited } \\
\text { the course in improving communication skills) }\end{array}$ \\
\hline $\begin{array}{l}\text { Analysis of Wikipedia } \\
\text { edits (students were } \\
\text { judged able to edit } \\
\text { Wikipedia content) }\end{array}$ & $\begin{array}{l}\text { Post-course survey (students were receptive to } \\
\text { the course) }\end{array}$ \\
\hline $\begin{array}{l}\text { Analysis of Wikipedia } \\
\text { edits }\end{array}$ & $\begin{array}{l}\text { - Post-course survey } \\
\text { - Interviews (students rated their satisfaction } \\
\text { with the course and their self-perceived knowl- } \\
\text { edge as high) }\end{array}$ \\
\hline
\end{tabular}

Post-course survey (students reported increased perception of Wikipedia's reliability, an inclination to encourage peers to edit Wikipedia, improved ability to practice EBM, and increased desire to contribute to the public good)

Analysis of student assignments
Post-course survey (students reported satisfaction with the experience and opportunity to contribute to Wikipedia, but also identified barriers related to mechanics of editing Wikipedia and difficulty engaging with Wikipedia community)

MUSC Medical University of South Carolina, UCFUniversity of Central Florida, UCSFUniversity of California, San Francisco

${ }^{a}$ Students used the information located or made over 1,000 unique edits.

sure of the quality of their learning, as well as their potential impact on Wikipedia [11-14]. Instructors also tracked the durability of student edits with regard to whether the edits were reversed and used this as an indicator of quality edits. In two notable instances, the instructors went further. Azzam utilized natural language processing software to compute a "readability" score of Wikipedia entries before and after student edits to evaluate students' ability to apply lessons provided on health literacy and communication skills [11]. Badgett evaluated student edits based on the publication types of the sources (e.g., systematic reviews) the students used to support their edits [14].

\section{Discussion}

Our findings indicate that Wikipedia editing courses introduce students to EBM skills and provide opportunities to apply these skills. Currently many learners initially encounter EBM in preclinical training [52, 53], which can make it difficult to appreciate its relevance to their future clinician roles [13, 54]. For example, critical appraisal, the process of systematically judging research for trustworthiness and relevance to a particular context [55], is often taught using tra- ditional approaches, such as journal clubs, that can seem disconnected from patient care. In contrast, the authentic experience of editing pages to be viewed by potentially thousands of readers is an intrinsically motivating approach to EBM $[13,56]$. However, a minority of courses explicitly referenced EBM, while the vast majority taught one or more EBM skills, speaking to a missed opportunity to make a direct link. Moreover, instructors should consider longitudinally assessing the integration of EBM in HPE such that learners' knowledge and behaviors are evaluated not only following the Wikipedia course, but also when students engage in clinical practice.

Editing Wikipedia's medical content requires editors to first interpret biomedical literature and second translate it into plain language interpretable across a spectrum of health literacy levels. These communication skills are similar to those that health professionals must use when sharing information with patients, skills which when effectively deployed have been shown to impact medical outcomes, safety, and patient satisfaction [57]. Several courses embedded health communication content. One course evaluated students' experience in attempting to simplify their language [11]. Future instructors might draw upon 
these courses and their targeted efforts on health literacy to further develop HPE students' communication skills, which have been documented as deficient upon graduation $[58,59]$.

In contributing to the formulation and sourcing of Wikipedia entries, HPE students are learning about medical epistemology (how health knowledge is assembled, verified, and effectively communicated). This may guide Wikipedia use in their own practice and better position them to support patients searching and interpreting online medical information. In this process, students attain a greater degree of learner autonomy by gaining an ability to critically assess Wikipedia's strengths and limits, with a new appreciation for the value of its sources. Moreover, students may gain an ability to rectify and enhance this public source as they have the potential for occasional edits and corrections of Wikipedia. Future directions include examining the extent to which the students' experiences with Wikipedia have contributed to their learner autonomy, especially around delving into Wikipedia's source materials, their guidance of patient's use of Wikipedia, and their contributions to it. A longitudinal study examining the effect different educational methods have on editor and instructor retention (students and professors who continue to improve Wikipedia or continue to teach new course iterations) is also warranted.

Inherent in these courses is the empowering and positioning of students as critics and moderators of knowledge. Indeed, all courses culminated in students critically appraising Wikipedia topics. However, there was variation in how much agency the students received toward that goal. For example, while many courses included peer-evaluation activities, which allowed for epistemic agency and shared evaluation [60-62], only half offered students opportunities to select the article they edited. Wikipedia offers great potential to instructors seeking methods of engaging learner autonomy in their courses and to medical practitioners who take Wikipedia courses to participate more readily in current medical discourse and to apply current medical knowledge in their clinical practice.

For patients, the principal practical implications of these courses are that the student involvement, with medical professional oversight, extends Wikipedia coverage of medical topics in range and depth, while adhering to standards for format, topics, and evidence. This means that patients have a greater chance of finding their conditions covered and in more detail. By having students follow a standard format, patients will also be better able to navigate the edited articles and other medical entries more readily. Moreover, these articles will present a high level of evidence that has had professional oversight in its selection and presentation. On a smaller scale, certainly, patients have a great chance of encountering a health professional, experienced with and knowledgeable about
Wikipedia, who can encourage and guide them in taking advantage of Wikipedia. We propose that this would enable them to be more informed patients, ready to participate in decision-making and other aspects of their health.

\section{Limitations}

While we systematically searched the literature and Wiki Edu's dashboards, we possibly missed initiatives, including those that may not have used a Wiki Edu dashboard. While the dashboards provided substantial course information, we were unable to capture some materials that were presented as external links or always identify instructors' professions. We were also unable to extract information on the quality of the final article edits, including how many met Wikipedia's guidelines.

We believe we identified the most robust sources of information available on these courses. However, we feel instructors would be challenged to adopt a course based on the identified dashboard or articles alone. We recommend course instructors consider making their materials freely available, perhaps by crafting MedEdPORTAL articles or sharing resources via FOAMed, which allow for sharing of detailed curricular materials and would enable instructors to readily examine available materials and make informed judgment on implementing those they deem appropriate. Additionally, future researchers might consider more in-depth qualitative study by interviewing course instructors to better understand the facilitators and barriers to integrating Wikipedia in HPE.

\section{Future directions}

Beyond using Wikipedia as a teaching platform and learning tool, these initiatives aimed to improve the quality of Wikipedia's medical pages; many of these are heavily accessed, which suggests their impact on public health. This speaks to the social contract between health professionals and society whereby providers have a responsibility to provide accurate scientific evidence and communicate effectively. Thus, ensuring edits are based on high-quality evidence presented in an unbiased neutral manner is a critical outcome for these courses. This public use of student-created health information has implications for Wikipedia and its editors, who also play a role in ensuring Wikipedia's quality through their edits and by providing quality assessments on each medical topic's talk page. As HPE instructors continue to offer courses and the volume of student edits increases, editors might consider partnering with courses to collaboratively assess pages, thus easing the workflow for editors and exposing learners to Wiki Project Medicine's robust assessment system [63].

We identified a single educational initiative that included a final step of an instructor or expert verifying and adjusting the final product to ensure that the 
Wikipedia articles were left with high quality contributions [11]. Our results indicate that some instructors included proactive measures to moderate the quality of the final edits, such as encouraging students to interact with and work with Wikipedia's medical editors, drafting contributions in My Sandbox, assessing contributions for readability and clear language, and peer reviewing suggested edits. Increased implementation of these measures, along with a final review of the live Wikipedia article following the editing initiative by a content expert, can help ensure that students are properly interpreting Wikipedia's guideline for reliable medical sources. This focus on quality will also improve student experiences and interactions with the Wikipedia volunteer community.

What appears to be missing from the use of Wikipedia editing in HPE is systematic forms of assessment and evaluation to substantiate both the gains in learning and in the quality of Wikipedia entries, and to assess learning in EBM and health communication. This study should inspire current and new instructors using Wikipedia to add these important elements to the curriculum. Through the Wiki Edu dashboard, there is already a common set of measures for words and references added among the HPE courses. To this, common strategies and instruments could be established among the instructors to establish a body of finding across different settings and cohorts, not so much as a means of grading the students, but as a way of comparing the effectiveness of teaching strategies among different populations of students. These might include pre-test and posttest exercises to furnish the students with a means of assessing changes, for example, in (a) how they would approach the use of Wikipedia by professionals and patients; (b) identifying key factors in constructing and communicating medical knowledge; (c) ways of learning a new topic; and (d) expertise on the topic on which they have contributed to Wikipedia, and (e) means of engaging in evidence-based practices. These assessments might also involve an extension of Azzam's deployment of outside experts [11] to assess a sample of editing changes for their quality, perhaps along dimensions of accuracy, evidence, and clarity. Such an approach, especially with some coordination among initiatives, might add to the evidence-based pedagogical practices behind HPE, which would be consistent with its own educational goals along EBM lines. To facilitate this goal, we encourage the formation of a special interest group in health professions education around the use of Wikipedia, which could lead to activities such as sharing assessment tools and other strategies.

\section{Conclusion}

In this study, we characterized and analyzed online curricular materials and the relevant literature to holistically describe courses offered to HPE stu- dents that utilize Wikipedia. These courses actively engage students in constructing EBM materials for the benefit of others, while learning about the nature and communication of medical knowledge. Based on the increasing number of these courses and instructors' willingness to continue offering them, there are grounds for more systematic assessments of their contributions to student learning and practices.

Funding This work was supported by funding through a Patient Centered Outcomes Research Institute (PCORI), Eugene Washington PCORI Engagement Award (EA\# SU12722).

Conflict of interest L.A. Maggio, J.M. Willinsky, J.A. Costello, N.A. Skinner, P.C. Martin and J.E. Dawson declare that they have no competing interests.

Open Access This article is licensed under a Creative Commons Attribution 4.0 International License, which permits use, sharing, adaptation, distribution and reproduction in any medium or format, as long as you give appropriate credit to the original author(s) and the source, provide a link to the Creative Commons licence, and indicate if changes were made. The images or other third party material in this article are included in the article's Creative Commons licence, unless indicated otherwise in a credit line to the material. If material is not included in the article's Creative Commons licence and your intended use is not permitted by statutory regulation or exceeds the permitted use, you will need to obtain permission directly from the copyright holder. To view a copy of this licence, visit http://creativecommons.org/licenses/by/4.0/.

\section{References}

1. Wikipedia. Wikipedia: statistics. https://en.wikipedia.org/ wiki/Wikipedia:Statistics. Accessed 8 Mar 2020.

2. Heilman JM, West AG. Wikipedia and medicine: quantifying readership, editors, and the significance of natural language. J Med Internet Res. 2015;17:e62.

3. Shafee T, Masukume G, Kipersztok L, Das D, Häggström M, Heilman J. Evolution of Wikipedia's medical content: past, present and future. J Epidemiol Community Health. 2017;71:1122-9.

4. Bylund CL, Gueguen JA, D'Agostino TA, Imes RS, Sonet E. Cancer patients' decisions about discussing Internet information with their doctors. Psychooncology. 2009;18:1139-46.

5. Laurent MR, Vickers TJ. Seeking health information online: does Wikipedia matter? J Am Med Inform Assoc. 2009;16:471-9.

6. Hughes B, Joshi I, LemondeH, WarehamJ.Junior physician's use of Web 2.0 for information seeking and medical education: a qualitative study. Int J Med Inform. 2009;78:645-55.

7. Heilman JM, Kemmann E, Bonert M, Chatterjee A, Ragar B, Beards GM, et al. Wikipedia: a key tool for global public health promotion. J Med Internet Res. 2011;13:e14.

8. Azzam A. Embracing Wikipedia as a teaching and learning tool benefits health professional schools and the populations theyserve. Innov GlobHealth ProfEduc. 2017. https:// doi.org/10.20421/ighpe2017.01

9. Herbert VG, Frings A, Rehatschek H, Richard G, Leithner A. Wikipedia-challenges and new horizons in enhancing medical education. BMCMedEduc. 2015; 15:32.

10. Metcalfe D, Powell J. Should doctors spurn Wikipedia? J Royal Soc Med. 2011;104:488-9. 
11. Azzam A, Bresler D, Leon A, Maggio L, Whitaker E, Heilman J, et al. Why medical schools should embrace Wikipedia: final-year medical student contributions to Wikipedia articles for academic credit at one school. Acad Med. 2017;92:194-200.

12. Apollonio DE, Broyde K, Azzam A, De Guia M, Heilman J, Brock T. Pharmacy students can improve access to quality medicines information by editing Wikipedia articles. BMC MedEduc. 2018;18:265.

13. Murray H, Walker M, Dawson J, Simper N, Maggio LA. Teaching evidence-based medicine to medical students using Wikipedia as a platform. Acad Med. 2020;95:382-6.

14. Badgett RG, Moore M. Are medical students able and willing to edit Wikipedia to learn components of evidence-based practice? Kans J Med. 2011;4:62-9.

15. Sackett DL, Rosenberg WM, Gray JM, Haynes RB, Richardson WS. Evidence based medicine: what it is and what it isn't. BMJ. 1996;312:71-2.

16. Straus S, Glasziou P, Richardson W, Haynes R. Evidence based medicine: how to teach and practice EBM. 5th ed. NewYork: Elsevier; 2018.

17. Tilson JK, Kaplan SL, Harris JL, Hutchinson A, Ilic D, Niederman R, et al. Sicily statement on classification and development of evidence-based practice learning assessment tools. BMCMedEduc. 2011;11:78.

18. Smith DA. Situating Wikipedia as a health information resource in various contexts: a scoping review. PLoS ONE. 2020;15:e228786.

19. Dang TM, Maggio LA. Supporting the call to action: a review of nutrition educational interventions in the health professions literature and MedEdPORTAL. Acad Med. 2017;92:403-16.

20. Wiki education dashboards. https://dashboard.wikiedu. org/explore. Accessed 4 Dec 2019.

21. Apollonio D. CP133 health policy. University of California, SanFrancisco, 2019. 2019. https:// dashboard.wikiedu.org/ courses/UCSF/CP133_Health_Policy_. Accessed 17 Mar 2020.

22. Apollonio D. Foundations II. University of California, San Francisco. 2019. https://dashboard.wikiedu.org/courses/ UCSF/Foundations_II_(Summer). Accessed 17 Mar 2020.

23. Azzam A. WikiMed Dec 2019 UCSF SOM. University of California, San Francisco. 2019. https://dashboard.wikiedu. org/courses/UCSF_School_of_Medicine/WikiMed_Dec_ 2019_UCSF_SOM_(Career_Launch_Block_9). Accessed 17 Mar 2020

24. Brennan E. WikiProject medicine-medical writing. Medical University of South Carolina. 2019. https:// dashboard.wikiedu.org/courses/Medical_University_of South_Carolina_-_MUSC/WikiProject_Medicine_-_Medi cal_Writing_(Winter). Accessed 17 Mar 2020.

25. Brock T. Words as power-expanding WikiProject pharmacology. University of California, San Francisco. 2016. https://dashboard.wikiedu.org/courses/University_of_ California,_San_Francisco/Words_as_Power_-_Expanding WikiProject_Pharmacology_(Fall_2016). Accessed 17 Mar 2020.

26. Brown L. Foundations of clinical trauma psychology fall quarter 2019. Palo Alto University. 2019. https:// dashboard.wikiedu.org/courses/Palo_Alto_University/ Foundations_of_Clinical_Trauma_Psychology_Fall_ Quarter2019_(Fall).Accessed 17 Mar 2020.

27. Butler K. Nursing 265 Introduction to nursing research and evidence-based practice. Grand Valley State University. 2017. https://dashboard.wikiedu.org/courses/Grand Valley_State_University/Nursing_265_Introduction_to_
Nursing_Research_and_Evidence-Based_Practice_(Fall_ 2017). Accessed 17 Mar 2020.

28. Etemad S. WikiMed fall 2019. Vanderbilt University. 2019. https://dashboard.wikiedu.org/courses/ Vanderbilt_University_School_of_Medicine/WikiMed_ Fall_2019_(Fall_2019).Accessed 17 Mar 2020.

29. Evenstein S. WikiMed elective at Tel Aviv University. Tel Aviv University. 2018. https://dashboard.wikiedu.org/ courses/Tel_Aviv_University/WikiMed_Elective_at_Tel_ Aviv_University_(Yearly). Accessed 17 Mar 2020.

30. Fasching F. Advanced pathophysiology. DeSales University. 2019. https://dashboard.wikiedu.org/courses/DeSales_ University/Advanced_Pathophysiology_(Fall_2019). Accessed 17Mar 2020.

31. Ginier E. Med communications Wikipedia October 2019 UMMS. University of Michigan. 2019. https:// dashboard. wikiedu.org/courses/University_of_Michigan_Medical_ School/Med_Communications_Wikipedia_October_2019 UMMS_(Fall). Accessed 17 Mar 2020.

32. Giulietti M. WesternU Wikiproject medicine WAVE. Western University. 2017. https://dashboard.wikiedu. org/courses/Western_University_of_Health_Sciences_ COMP/WesternU_Wikiproject_Medicine_WAVE_(Summer_ 2017). Accessed 17 Mar 2020.

33. Jackson R. IPPE III pharmacy literature review. Xavier University. 2017. https:/ / dashboard.wikiedu.org/courses/ XULACOP/IPPE_III_Pharmacy_Literature_Review_(PILOT). Accessed 17 Mar 2020.

34. Kahili-HeedeM.JABSOMMS1 Wikipedia editing 2019. University of Hawaii. 2019. https://dashboard.wikiedu.org/ courses/University_of_Hawaii/JABSOM_MS1_Wikipedia_ Editing_2019_(Fall). Accessed 17 Mar 2020.

35. Larson M. NURS 851. Clarion and Edinboro Universities. 2019. https://dashboard.wikiedu.org/courses/ Clarion_and_Edinboro_Universities/NURS_851_(FallSpring)/home. Accessed 17 Mar 2020.

36. Lebowitz D. WikiProject medicine fall 2019 UCF COM. University of Central Florida. 2019. https://dashboard. wikiedu.org/courses/University_of_Central_Florida_ College_of_Medicine/WikiProject_Medicine_Fall_2019_ UCF_COM_(FALL).Accessed 17 Mar 2020.

37. Lorbeer E. BIOM 9220-2-expanded WikiProject medicine. Western Michigan University. 2019. https://dashboard. wikiedu.org/courses/Western_Michigan_University_ Homer_Styker_MD_School_of_Medicine/BIOM_9220-2__Expanded_WikiProject_Medicine_(October_21_to_No vember_18,2019). Accessed 17 Mar 2020.

38. Lorbeer E. Medical translation. Western Michigan University. 2019. https://dashboard.wikiedu.org/courses/ Western_Michigan_University_School_of_Medicine/ Medical_Translation_(September_23_to_October_20,_2019). Accessed 17 Mar 2020.

39. Manson S. Medical City Weatherford WikiMed project. University of North Texas. 2019. https://dashboard. wikiedu.org/courses/UNTHSC,_TCOM/Medical_City_ Weatherford_WikiMed_Project_(Spring_Semester_-_18_ weeks). Accessed 17 Mar 2020.

40. Meinke D. Hearing loss prevention 2018. University of Northern Colorado. 2018. https://dashboard.wikiedu. org/courses/University_of_Northern_Colorado/Hearing Loss_Prevention_2018_(Fall). Accessed 17 Mar 2020.

41. Paskausky A. N603-theoretical comparisons in nursing science. University of Massachusetts at Amherst. 2017. https://dashboard.wikiedu.org/courses/University_of_ Massachusetts_Amherst/N603-Theoretical_Comparisons in_Nursing_Science_(Summer_2017). Accessed 17 Mar 2020 . 
42. Richards M. RMC Summer research fellowship 2017. Rush University. 2017. https://dashboard.wikiedu.org/courses/ Rush_University_Medical_Center/RMC_Summer_Re search_Fellowship_2017_(Summer_2017). Accessed 17 Mar 2020.

43. Roach A. Graduate neuroscience. University of South Carolina. 2019. https://dashboard.wikiedu.org/courses/ University_of_South_Carolina_Aiken/Graduate_Neuro science_(Fall_2019).Accessed 17 Mar 2020.

44. Tran M. Wikipedia in medicine and science. Icahn School of Medicine. 2019. https://dashboard.wikiedu.org/ courses/Icahn_medicine_at_Mount_Sinai/Wikipedia_in Medicine and Science_(Fall_2019). Accessed 17Mar 2020.

45. Wakefield E. Hearing conservation. University of Nebraska Lincoln. 2019. https://dashboard.wikiedu.org/courses/ University_of_Nebraska_Lincoln/Hearing_Conservation (Spring_2019). Accessed 17 Mar 2020.

46. Wolozin B. Systems pharmacology I. Boston University. 2019. https://dashboard.wikiedu.org/courses/Boston_ University_School_of_Medicine/Systems_Pharmacology_ I_2019_(Fall,_2019).Accessed 17 Mar 2020.

47. Yeager S. NURS 495-13 and 14. Rockford University. 2018. https://dashboard.wikiedu.org/courses/Rockford University/NURS_495-13_and_14_(Fall_2018). Accessed 17 Mar 2020.

48. Joshi M, Verduzco R, Yogi S, Garcia M, et al. Wikipedia editingcourses at threeUSmedicalschools in the2017-2018 academicyear. MedEdPublish. 2019;8:76.

49. Evenstein Sigalov S, Nachmias R. Wikipedia as a platform for impactful learning: a new course model in higher education. Educ InfTechnol. 2017;22:2959-79.

50. Wikipedia. Wikipedia: five pillars. https://en.wikipedia. org/wiki/Wikipedia:Five_pillars. Accessed 25 Feb 2020.

51. Wikipedia. Wikipedia assignment assessment: a guide for evaluating student contributions to Wikipedia. https:// upload.wikimedia.org/wikipedia/commons/d/d2/Wiki Education_Classroom_Program_example_grading_rubric pdf. Accessed 27 Feb2020.

52. Maggio LA, Tannery NH, Chen HC, ten CateO, O'Brien B.Evidence-based medicine training in undergraduate medical education: a review and critique of the literature published 2006-2011. Acad Med. 2013;88:1022-8.

53. Ilic D, Maloney S. Methods of teaching medical trainees evidence-based medicine: a systematic review. Med Educ. 2014;48:124-35.

54. Maggio LA, Capdarest-Arest N. Practising evidence-based medicine (EBM): a descriptive analysis of medical students' whole-task EBM assignments. Evid Based Med. 2017;22:41-4.

55. What is critical appraisal?. https://www.whatisseries.co. uk/what-is-critical-appraisal/. Accessed 14 July 2020.

56. Maggio LA, Willinsky JM, Steinberg RM, Mietchen D, Wass JL, Dong T. Wikipedia as a gateway to biomedical research: the relative distribution and use of citations in the English Wikipedia. PLoS ONE. 2017;12:e190046.

57. BoissyA, Windover AK, Bokar D, etal. Communication skills training for physicians improves patient satisfaction. J Gen Intern Med. 2016;31:755-61.

58. Bachmann C, Roschlaub S, Harendza S, Keim R, Scherer M. Medical students' communication skills in clinical education: results from a cohort study. Patient Educ Couns. 2017;100:1874-81.

59. Expósito JS, Costa CL, Díaz-Agea JL, Carrillo-Izquierdo MD, Rodríguez DJ. Ensuring relational competency in critical care: importance of nursing students' communication skills. Intensive Crit Care Nurs. 2018;44:85-91.

60. Stroupe D. Examining classroom science practice communities: how teachers and students negotiate epistemic agency and learn science-as-practice. Sci Educ. 2014;98:487-516.

61. Aukerman MS. When reading it wrong is getting it right: shared evaluation pedagogy among struggling fifth grade readers. Res Teach Engl. 2007;42:56-103.

62. Aukerman M, Martin PC, Gargani J, McCallum RD. A randomized control trial of shared evaluation pedagogy: the near-term and long-term impact of dialogically organized reading instruction. Educ Stud Lang Lit. 2016;16:1-26.

63. WikiProject Medicine. WikiProject medicine: assessment https://en.wikipedia.org/wiki/Wikipedia:WikiProject_ Medicine/Assessment. Accessed 14 July 2020. 